\title{
3,3'-Diindolylmethane inhibits VEGF expression through the HIF-1 $\alpha$ and NF-кB pathways in human retinal pigment epithelial cells under chemical hypoxic conditions
}

\author{
HONGZOO PARK ${ }^{1}$, DAE-SUNG LEE ${ }^{2}$, MI-JIN YIM ${ }^{2}$, YUNG HYUN CHOI ${ }^{3}$, SAEGWANG PARK $^{4}$, \\ SU-KIL SEO ${ }^{4}$, JUNG SIK CHOI ${ }^{5}$, WON HEE JANG ${ }^{6}$, SUNG SU YEA ${ }^{6}$, WON SUN PARK ${ }^{7}$, \\ CHANG-MIN LEE ${ }^{8}$, WON-KYO JUNG ${ }^{9}$ and IL-WHAN CHOI ${ }^{4}$
}

\author{
${ }^{1}$ Department of Urology, Kangwon National University Hospital, Kangwon National University \\ School of Medicine, Chuncheon, Gangwon-do; ${ }^{2}$ Marine Biodiversity Institute of Korea, Seocheon, \\ Chungcheongnam-do; ${ }^{3}$ Department of Biochemistry, College of Oriental Medicine, Dongeui University; \\ ${ }^{4}$ Department of Microbiology, College of Medicine, Inje University; ${ }^{5}$ Department of Internal Medicine, \\ Busan Paik Hospital, College of Medicine, Inje University; ${ }^{6}$ Department of Biochemistry, College of Medicine, \\ Inje University, Busan; ${ }^{7}$ Department of Physiology, Kangwon National University School of Medicine, Chuncheon, \\ Gangwon-do, Republic of Korea; ${ }^{8}$ Department of Molecular Microbiology and Immunology, Warren Alpert \\ School of Medicine, Providence, RI, USA; ${ }^{2}$ Department of Biomedical Engineering and Center for Marine- \\ Integrated Biomedical Technology (BK21 Plus), Pukyong National University, Busan, Republic of Korea
}

Received February 15, 2015; Accepted April 30, 2015

DOI: $10.3892 / \mathrm{ijmm} .2015 .2202$

\begin{abstract}
Oxidative stress in the retinal pigment epithelium (RPE) can lead to the pathological causes of age-related macular degeneration (AMD). Hypoxia induces oxidative damage in retinal pigment epithelial cells (RPE cells). In this study, we investigated the capacity of 3,3'-diindolylmethane (DIM) to reduce the expression of vascular endothelial growth factor (VEGF) under hypoxic conditions, as well as the molecular mechanisms involved. Human RPE cells (ARPE-19 cells) were treated with cobalt chloride $\left(\mathrm{CoCl}_{2}, 200 \mu \mathrm{M}\right)$
\end{abstract}

Correspondence to: Professor Il-Whan Choi, Department of Microbiology, College of Medicine, Inje University, 75 Bokji-Ro, Busanjin-gu, Busan 614-735, Republic of Korea

E-mail: cihima@inje.ac.kr

Professor Won-Kyo Jung, Department of Biomedical Engineering and Center for Marine-Integrated Biomedical Technology (BK21 Plus), Pukyong National University, 45 Yongso-ro, Nam-gu, Busan 608-737, Republic of Korea

E-mail: wkjung@pknu.ac.kr

Abbreviations: AMD, age-related macular degeneration; $\mathrm{CoCl}_{2}$, cobalt chloride; $\mathrm{CNV}$, choroidal neovascularization; VEGF, vascular endothelial growth factor; DIM, 3,3'-diindolylmethane; RPE, retinal pigment epithelium; HIF-1 $\alpha$, hypoxia-inducible factor- $1 \alpha$; MAPKs, mitogen-activated protein kinases; ROS, reactive oxygen species

Key words: 3,3'-diindolylmethane, hypoxia, vascular endothelial growth factor, retinal pigment epithelial cells, choroidal neovascularization, age-related macular degeneration and/or DIM (10 and $20 \mu \mathrm{M})$. The production of VEGF was measured by enzyme-linked immunosorbent assay. The translocation of hypoxia-inducible factor-1 $\alpha$ (HIF-1 $\alpha$ ) and nuclear factor- $\kappa \mathrm{B}(\mathrm{NF}-\mathrm{\kappa B})$ was determined by western blot analysis. The binding activity of HIF- $1 \alpha$ and NF- $\mathrm{KB}$ was analyzed by electrophoretic mobility shift assay. The phosphorylation levels of mitogen-activated protein kinases (MAPKs) were measured by western blot analysis. The levels of mitochondrial reactive oxygen species (ROS) were detected by fluorescence microplate assay. The results revealed that DIM significantly attenuated the $\mathrm{CoCl}_{2}$-induced expression of VEGF in the ARPE-19 cells. The $\mathrm{CoCl}_{2}$-induced translocation and activation of HIF-1 $\alpha$ and NF- $\kappa B$ were also attenuated by treatment with DIM. In addition, DIM inhibited the $\mathrm{CoCl}_{2}$-induced activation of p38 MAPK in the ARPE-19 cells. Pre-treatment with YCG063, a mitochondrial ROS inhibitor, led to the downregulation of the $\mathrm{CoCl}_{2}$-induced production of VEGF by suppressing HIF-1 $\alpha$ and NF- $\mathrm{KB}$ activity. Taken together, the findings of our study demonstrate that DIM inhibits the $\mathrm{CoCl}_{2}$-induced production of VEGF by suppressing mitochondrial ROS production, thus attenuating the activation of HIF- $1 \alpha$ and $\mathrm{p} 38$ MAPK/NF- $\mathrm{\kappa B}$.

\section{Introduction}

Age-related macular degeneration (AMD) is a progressive eye condition and the leading cause of severe vision loss that affects the macula, which is the light-sensitive nerve tissue lining at the back of the eye in the retina, in older adults. AMD causes a number of complications, such as blurriness, dark areas or distortion, with central vision (1). Choroidal neovascularization $(\mathrm{CNV})$ is a common symptom of the 'wet' form of AMD, which is the more advanced type of AMD. CNV involves 
the sprouting of new blood vessels that originate from the choroid under the macula that move through a break in Bruch's membrane and retinal pigment epithelium (RPE) to reach the subretinal space (2). These blood vessels leak blood and fluid that damages photoreceptor cells. The overexpression of vascular endothelial growth factor (VEGF), a potent vascular endothelial cell mitogen, appears to play a role in the development of CNV. The RPE is a monolayer of pigmented cells of the retina. Retinal pigment epithelial cells (RPE cells) play an important role in the phagocytosis of shedded photoreceptor membranes, the transport of nutrients from the vascular choroid, the formation of the blood-retinal barrier and in the absorption of scattered light (3).

Hypoxia, a condition in which the body is deprived of a sufficient oxygen supply, is a potent inducer of VEGF overexpression through an accumulation of hypoxia-inducible factors (HIFs) in CNV (4). HIF-1 consists of an oxygen-regulated inducible HIF-1 $\alpha$ subunit and a constitutively expressed HIF-1 $\beta$ subunit. Under hypoxic conditions, HIF-1 $\alpha$ is stabilized and accumulates. It then dimerizes with HIF-1 $\beta$ and translocates to the nucleus, forming the active HIF complex (5). Activated HIF then binds to a hypoxia response element (HRE) and activates the transcription of target genes, such as VEGF, which is a critical pathogenic factor in CNV (4). Therefore, the inhibition of the HIF pathway may be an attractive therapeutic strategy for CNV.

3,3'-Diindolylmethane (DIM) (Fig. 1A) is a major compound that is derived from the digestion of indole-3-carbinol, which is found in cruciferous vegetables, such as broccoli, Brussels sprouts, cabbage, cauliflower and kale (6). DIM has been shown to have numerous potential anti-cancer properties in breast, prostate and colorectal cancer (7-9). Although DIM has been shown to exert anti-angiogenic effects (10), to the best of our knowledge, there are no available studies to date on the effects of DIM on CNV. Thus, in the present study, we investigated the anti-angiogenic effects of DIM and its effects on signaling pathways using the human RPE cell line, APRE-19.

\section{Materials and methods}

Reagents. Cobalt chloride $\left(\mathrm{CoCl}_{2}\right)$, diphenyleneiodonium (DPI), $\mathrm{N}$-acetyl-L-cysteine (NAC), U0126 [an extracellular signal-regulated kinase (ERK)1/2 inhibitor] and DIM were purchased from Sigma Chemical Co. (St. Louis, MO, USA). YCG063 [a mitochondrial reactive oxygen species (ROS) inhibitor] was obtained from Millipore (Billerica, MA, USA). SB203580 [a p38 mitogenactivated protein kinase (MAPK) inhibitor] and SP600126 (a JNK inhibitor) were purchased from Enzo Life Sciences, Inc. (Farmingdale, NY, USA). PX-478 (an HIF-1 $\alpha$ inhibitor) was purchased from MedKoo Biosciences, Inc. (Chapel Hill, NC, USA). Mito PY1 was purchased from Tocris Biosience (Bristol, UK). BAY 11-7082 and parthenolide [nuclear factor (NF) $-\kappa B$ inhibitors] were purchased from Santa Cruz Biotechnology, Inc. (Santa Cruz, CA, USA). An antibody against p65 was obtained from eBioscience (Cat. no. 14-6731; San Diego, CA, USA). An antibody against HIF-1 $\alpha$ was obtained from Novus Biologicals (Cat. no. NB100-105; Littleton, CO, USA). Antibodies against phosphorylated (p)-ERK1/2 (Cat. no. 9106) and p-p38 MAPK (Cat. no. 9211) were purchased from Cell Signaling Technology (Beverly, MA, USA). Antibodies against ERK1/2 (Cat. no. sc-94) and p38 MAPK (Cat. no. sc-535) were purchased from Santa
Cruz Biotechnology, Inc. Nitrocellulose membranes and an enhanced chemiluminescence (ECL) kit were obtained from Amersham Pharmacia Biotech (Uppsala, Sweden).

ARPE-19 cell culture. The ARPE-19 cells were obtained from the American Type Culture Collection (Manassas, VA, USA) and cultured in DMEM/F12 medium supplemented with $10 \%$ fetal bovine serum plus a $100 \mathrm{IU} / \mathrm{ml}$ penicillin and $100 \mu \mathrm{g} / \mathrm{ml}$ streptomycin mixture (Gibco/BRL, Gaithersburg, $\mathrm{MD}, \mathrm{USA})$ in a humidified atmosphere $\left(5 \% \mathrm{CO}_{2}\right)$ at $37^{\circ} \mathrm{C}$. The ARPE-19 cells were trypsinized, seeded in $10-\mathrm{cm}$ diameter dishes and incubated overnight until attachment.

Cell viability assay. The viability of the ARPE-19 cells was determined using the cell counting kit-8 (CCK-8) according to the manufacturer's instructions (Dojindo Laboratories, Kumamoto, Japan). Briefly, the cells were seeded in triplicate at a density of $1 \times 10^{4}$ cells/well into 96-well culture plates and allowed to attach overnight. The cells were then incubated with the indicated concentrations of DIM or $200 \mu \mathrm{M}$ of $\mathrm{CoCl}_{2}$ alone (to induce chemical hypoxia) or were treated with DIM for 30 min prior to treatment with $\mathrm{CoCl}_{2}$. The plates were incubated for $24 \mathrm{~h}$ and $10 \mu \mathrm{l}$ of CCK- 8 reagent were added to each well. Following incubation for a further $2 \mathrm{~h}$ at $37^{\circ} \mathrm{C}$, the plates were read at $450 \mathrm{~nm}$ using a microplate reader (Model EL800; Bio-Tek, Winooski, VT, USA).

Depletion of HIF-1 $\alpha$ by synthetic small interfering RNA (siRNA). HIF-1 $\alpha$-specific siRNA were purchased from Santa Cruz Biotechnology, Inc. (Cat. no. sc-35561). Control siRNA-A (Cat.no. sc-37007; Santa Cruz Biotechnology, Inc.) was used as a negative control. In brief, $16 \mathrm{~h}$ after plating, the cells were transfected with $20 \mathrm{nM}$ HIF-1 $\alpha$-siRNA or control siRNA-A using siRNA transfection reagent (Santa Cruz Biotechnology, Inc.) in accordance with the manufacturer's instructions. Following $6 \mathrm{~h}$ of incubation, an equal volume of normal growth medium was added. Sixteen hours following transfection, the cells were used for the experiments mentioned below. The transfection efficiency was evaluated by determining HIF-1 $\alpha$ protein expression using western blot analysis.

Enzyme-linked immunosorbent assay (ELISA). VEGF levels in the cell culture medium were assessed by ELISA. The cells were treated with various concentrations of DIM for $30 \mathrm{~min}$ prior to $\mathrm{CoCl}_{2}$ stimulation. Following incubation for $24 \mathrm{~h}$ under hypoxic conditions, the culture supernatants were collected. The VEGF levels were measured using a VEGF DuoSet ELISA Development kit (R\&D Systems, Minneapolis, MN, USA) according to the manufacturer's instructions. The absorbance at $450 \mathrm{~nm}$ was determined using a microplate reader (Model EL800; Bio-Tek).

Western blot analysis. Western blot analysis was carried out as previously described (11). The ARPE-19 cells were washed 3 times with PBS and lysed with lysis buffer (Mammalian Cell-PE LB; G-Biosciences, St. Louis, MO, USA). Equal amounts of protein were separated on $10 \%$ sodium dodecyl sulfate (SDS)-polyacrylamide minigels and transferred onto nitrocellulose transfer membranes. Following incubation with the appropriate primary antibody, the membranes were incubated for $1 \mathrm{~h}$ at room temperature with a secondary antibody 
A<smiles>c1ccc2c(Cc3c[nH]c4ccccc34)c[nH]c2c1</smiles>

Chemical structure of DIM

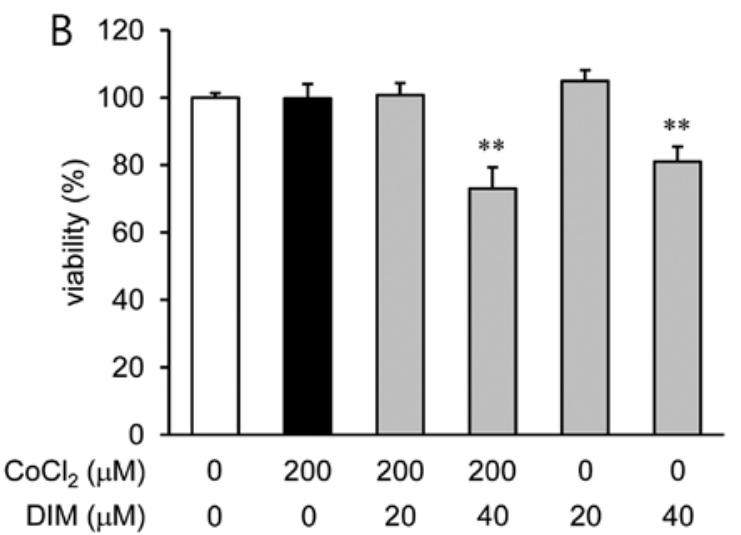

Figure 1. Effect of 3,3'-diindolylmethane (DIM) and cobalt chloride $\left(\mathrm{CoCl}_{2}\right)$ on the viability of ARPE-19 cells. (A) Chemical structure of DIM. (B) Cells were treated with $200 \mu \mathrm{M} \mathrm{CoCl}_{2}$ in the absence or presence of various concentrations of DIM. After $24 \mathrm{~h}$, cell viability was assessed using the cell counting kit- 8 assay. The results are expressed as the percentage of surviving cells over the control cells (without the addition of DIM under normoxic conditions). Each value indicates the mean \pm SEM and is representative of the results obtained from 3 independent experiments. ${ }^{* *}<<0.01$ vs. the control $\left(\mathrm{CoCl}_{2}\right.$ free $)$.

conjugated to horseradish peroxidase [goat anti-mouse IgG (Cat. no. sc-2031; Santa Cruz Biotechnology, Inc.) and donkey anti-rabbit IgG (Cat. no. A16035, Pierce, Rockford, IL, USA)]. Following 3 washes in Tris-buffered saline Tween-20 (TBST), the immunoreactive bands were visualized using the ECL detection system (Pierce).

Assay of mitochondrial ROS levels. The ARPE-19 cells $\left(1 \times 10^{4}\right.$ cells/well) were seeded in 96 -well plates in a humidified atmosphere containing $5 \% \mathrm{CO}_{2}$ at $37^{\circ} \mathrm{C}$ for $16 \mathrm{~h}$. Following $16 \mathrm{~h}$ of incubation, the cells were treated with $5 \mu \mathrm{M}$ Mito PY1 for $30 \mathrm{~min}$ and further incubated for $24 \mathrm{~h}$ with $\mathrm{CoCl}_{2}$. The cells were then immediately evaluated. The mitochondrial ROS levels were measured using a fluorescence microplate reader (SpetraMax M2; Molecular Devices, Sunnyvale, CA, USA) at an excitation wavelength of $485 \mathrm{~nm}$ and an emission wavelength of $538 \mathrm{~nm}$.

Preparation of nuclear extracts and electrophoretic mobility shift assay (EMSA). Nuclear extracts were prepared using NE-PER nuclear extraction reagent (Pierce). As a probe for the gel retardation assay, an oligonucleotide containing the immunoglobulin $\kappa$-chain binding site $(\kappa \mathrm{B}, 5$ '-GATCTCAGA GGGGACTTTCCGAGAGA-3') was synthesized. A typical double-stranded oligonucleotide for the HIF-1 $\alpha$ binding DNA sequence (5'-TCTGTACGTGACCACACTCACCTC-3') was purchased from Santa Cruz Biotechnology, Inc. (Cat. no. sc-2625). A non-radioactive method in which the 3 ' end of the probe was labeled with biotin was used in these experiments (Pierce). The binding reactions contained $5 \mu \mathrm{g}$ of nuclear extract protein, buffer (10 mM Tris, $\mathrm{pH} 7.5,50 \mathrm{mM} \mathrm{KCl}, 5 \mathrm{mM} \mathrm{MgCl}_{2}, 1 \mathrm{mM}$

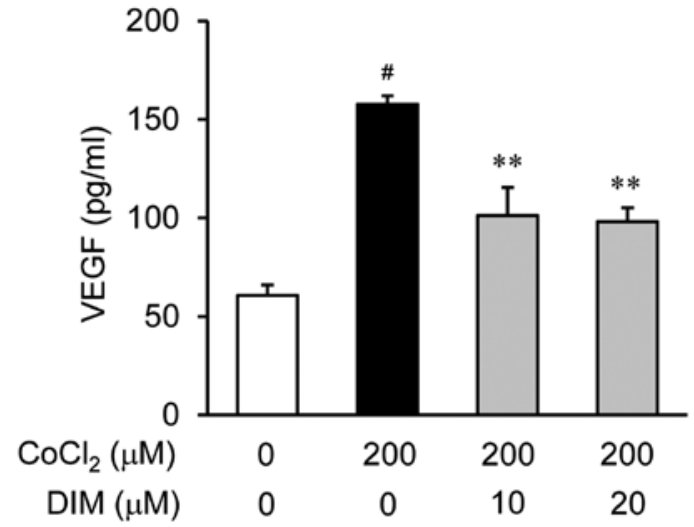

Figure 2. Effect of 3,3'-diindolylmethane (DIM) on cobalt chloride $\left(\mathrm{CoCl}_{2}\right)$ stimulated vascular endothelial growth factor (VEGF) production in ARPE-19 cells. The levels of VEGF in the culture medium were determined by enzymelinked immunosorbent assay (ELISA). The cells were pre-treated with DIM (10 or $20 \mu \mathrm{M}$ ) for 30 min prior to stimulation with $\mathrm{CoCl}_{2}$ for $24 \mathrm{~h}$. Each bar represents the mean \pm SEM from 3 independent experiments. ${ }^{\#} \mathrm{p}<0.05$ vs. the control $\left(\mathrm{CoCl}_{2}\right.$ free $) ;{ }^{* *} \mathrm{p}<0.01$ vs. $\mathrm{CoCl}_{2}$ stimulation.

dithiothreitol, $0.05 \%$ Nonidet P-40 and 2.5\% glycerol), $50 \mathrm{ng}$ of poly $(\mathrm{dI}-\mathrm{dC})$ and $20 \mathrm{fM}$ of the biotin-labeled DNA. The reactions were incubated for $20 \mathrm{~min}$ at room temperature in a final volume of $20 \mu \mathrm{l}$. The competition reactions were conducted by the addition of 100-fold excess of unlabeled NF- $\kappa B$ p 65 and 25 -fold excess of unlabeled HIF-1 $\alpha$ to the reaction mixture. The mixture was then separated by electrophoresis on a $5 \%$ polyacrylamide gel in $0.5 \mathrm{X}$ Tris-borate buffer and transferred onto nylon membranes. The biotin-labeled DNA was detected using a LightShift chemiluminescent EMSA kit (Pierce).

Statistical analysis. Data values represent the means \pm standard error of the mean (SEM). The statistical significance of the differences between the data sets was evaluated using ANOVA. Data were analyzed and plotted on graphs using GraphPad Prism software (GraphPad Software, La Jolla, CA, USA). A value of $\mathrm{p}<0.05$ was considered to indicate a statistically significant difference.

\section{Results}

Effects of DIM on the viability of human ARPE-19 cells. We examined the viability of human ARPE-19 cells pre-treated with DIM (20 and $40 \mu \mathrm{M}$ ) by CCK-8 assay under normoxic (no $\left.\mathrm{CoCl}_{2}\right)$ or hypoxic conditions $\left(\mathrm{CoCl}_{2}\right)$. DIM was not cytotoxic to the human ARPE-19 cells at concentrations of up to $20 \mu \mathrm{M}$; however, the cell viability was reduced by $19 \%$ with the dose of $40 \mu \mathrm{M}$ of DIM (Fig. 1B) under both normoxic and hypoxic conditions. Based on these results, a concentration lower than $20 \mu \mathrm{M}$ of DIM was selected for the subsequent experiments.

Effects of DIM on VEGF production under hypoxic conditions. To examine the anti-angiogenic properties of DIM and its effects on the $\mathrm{CoCl}_{2}$-induced production of VEGF in the ARPE-19 cells, we measured the secretion of VEGF into the culture medium using ELISA. The ARPE-19 cells were treated with various concentrations of DIM $(0,10$ or $20 \mu \mathrm{M})$ for $30 \mathrm{~min}$ prior to stimulation with $200 \mu \mathrm{M} \mathrm{CoCl}_{2}$ for $24 \mathrm{~h}$ (Fig. 2). As 
A

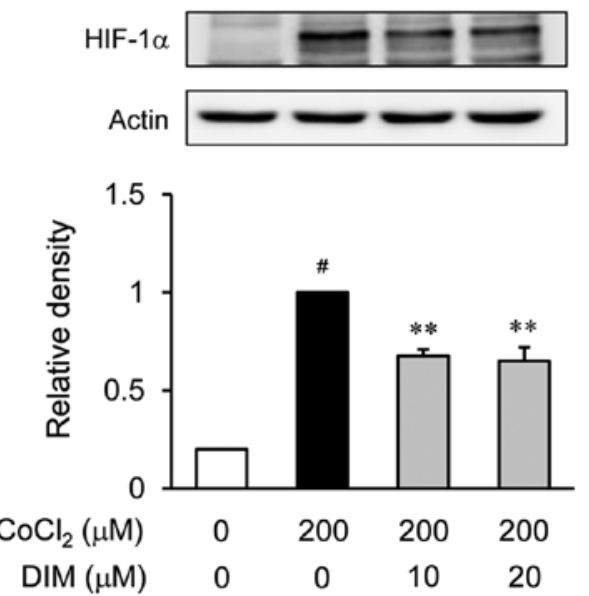

B

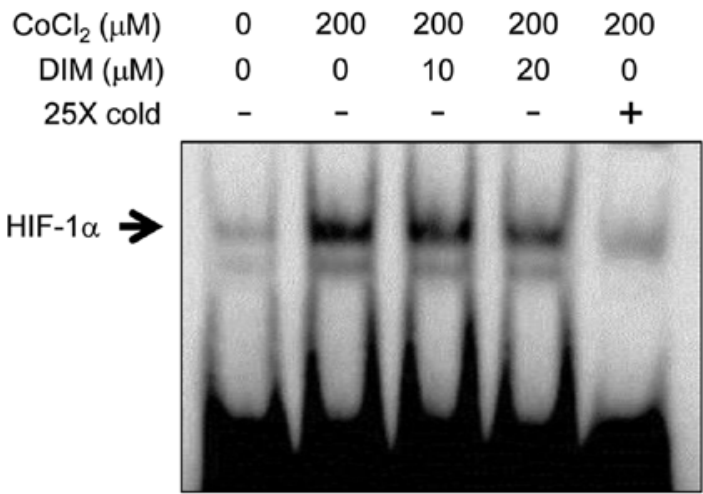

C

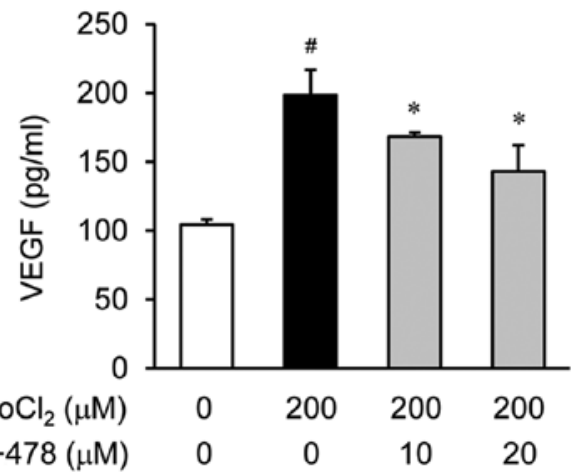

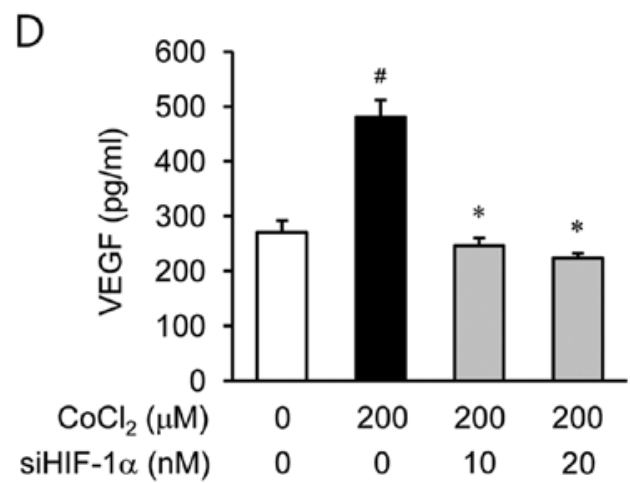

Figure 3. Inhibition of the cobalt chloride $\left(\mathrm{CoCl}_{2}\right)$-induced activation of hypoxia-inducible factor (HIF)-1 $\alpha$ by 3,3'-diindolylmethane (DIM) in ARPE-19 cells. (A) The HIF-1 $\alpha$ levels in the nuclear protein extracts were determined by western blot analysis. ARPE-19 cells were treated with DIM (10 or $20 \mu \mathrm{M}) 30 \mathrm{~min}$ prior to $\mathrm{CoCl}_{2}$ stimulation for $6 \mathrm{~h}$, and HIF-1 $\alpha$ was detected with its specific antibody. ${ }^{*} \mathrm{p}<0.05$ vs. control $\left(\mathrm{CoCl}_{2}\right.$ free) ${ }^{*}{ }^{* *} \mathrm{p}<0.01 \mathrm{vs}$. CoCl ${ }_{2}$ stimulation. (B) Nuclear protein extracts $(5 \mu \mathrm{g})$ were prepared and analyzed for the DNA binding activity of HIF-1 $\alpha$ using electrophoretic mobility shift assay (EMSA). ARPE-19 cells were treated with DIM for $30 \mathrm{~min}$ prior to $\mathrm{CoCl}_{2}$ stimulation for $6 \mathrm{~h}$. The results shown are representative of 3 independent experiments. $25 \mathrm{X}$ cold indicates the molar fold excess of the specific competitor. To determine whether the observed shifted bands are specific for HIF-1 $\alpha$, competition tests are run: to a protein extract that displays intense shifted bands, additionally to the labeled HIF-1 $\alpha$ probe a non-labeled ('cold') oligonucleotide is added in excess. Cold competition oligonucleotides are used that either contain the wild type HIF- $1 \alpha$ recognition site. If the observed signals are HIF-1 $\alpha$-specific, those signals should disappear in the presence of the cold HIF-1 $\alpha$ wild-type competitor. (C) ARPE-19 cells were treated with various concentrations of PX-478, a HIF-1 $\alpha$ inhibitor, for 30 min and were then stimulated with $\mathrm{CoCl}_{2}$ for $24 \mathrm{~h}$. Vascular endothelial growth factor (VEGF) production was measured using the corresponding enzyme-linked immunosorbent assay (ELISA) kits. " $\mathrm{p}<0.05$ vs. control $\left(\mathrm{CoCl}_{2}\right.$ free); ${ }^{\mathrm{p}}<0.05$ vs. $\mathrm{CoCl}_{2}$ stimulation. (D) Knockdown of HIF-1 $\alpha$ was performed using siRNA, and the production of VEGF was estimated by ELISA in ARPE-19 cells. ${ }^{*} \mathrm{p}<0.05$ vs. the control $\left(\mathrm{CoCl}_{2}\right.$ free); ${ }^{*} \mathrm{p}<0.05$ vs. $200 \mu \mathrm{M} \mathrm{CoCl}_{2}$ stimulation.

revealed by the VEGF measurements obtained using ELISA, the VEGF levels were significantly increased in the ARPE-19 cells following $24 \mathrm{~h}$ of exposure to hypoxic conditions $\left(\mathrm{CoCl}_{2}\right)$ compared to normoxic conditions (no $\mathrm{CoCl}_{2}$; by approximately 3 -fold); this increase was reversed by treatment with DIM in a dose-dependent manner.

Effects of DIM on HIF-1 $\alpha$ activation under hypoxic conditions. To determine whether DIM inhibits HIF-1 $\alpha$ translocation, the ARPE-19 cells were incubated with DIM $(10$ or $20 \mu \mathrm{M})$ under hypoxic conditions for $6 \mathrm{~h}$ (Fig. 3A). The $200 \mu \mathrm{M}$ $\mathrm{CoCl}_{2}$-stimulated ARPE-19 cells elicited an almost 5-fold increase in the translocation of HIF-1 $\alpha$ to the nuclei compared to the cells under normoxic conditions. By contrast, pre-treatment of the cells with DIM (10 or $20 \mu \mathrm{M})$ significantly inhibited the translocation of HIF-1 $\alpha$ under hypoxic conditions. Further experiments were carried out to determine whether the activation of HIF-1 $\alpha$ in the ARPE-19 cells is altered under hypoxic conditions by pre-treatment with DIM. When the nuclear extract proteins from the cells were probed with oligonucleotides within the VEGF promoter, a subsequent gel shift analysis revealed that the ARPE-19 cells displayed a marked increase in HIF-1 $\alpha$ binding activity under hypoxic conditions (Fig. 3B). However, the induction of specific HIF- $1 \alpha$ DNA binding activity following stimulation with $\mathrm{CoCl}_{2}$ was inhibited by treatment with DIM (10 or $20 \mu \mathrm{M})$. These results indicate that DIM inhibits HIF-1 $\alpha$ activity by preventing the translocation of this transcription factor to the nucleus during hypoxic conditions. To evaluate whether HIF- $1 \alpha$ is a critical factor in the expression of VEGF, PX-478 (10 or $20 \mu \mathrm{M}$ ), an HIF-1 $\alpha$ inhibitor (Fig. 3C), and siHIF-1 $\alpha$ (10 or $20 \mathrm{nM}$ ), siRNA against HIF-1 $\alpha$ (Fig. 3D), were used. As expected, the secretion of VEGF was significantly decreased following the inhibition of HIF- $1 \alpha$.

Involvement of mitochondrial ROS in the secretion of VEGF through HIF-1 $\alpha$ in $\mathrm{CoCl}_{2}$-stimulated ARPE-19 cells. To examine the role of ROS in the $\mathrm{CoCl}_{2}$-stimulated secretion of VEGF, the ARPE-19 cells were treated with various inhibitors 
of ROS, such as NAC for ROS scavengers, DPI as an NADPH oxidase inhibitor and YCG063 as a mitochondrial ROS inhibitor, prior to $\mathrm{CoCl}_{2}$ stimulation. NAC and DPI had no effect on VEGF production during hypoxia (Fig. 4A). However, YCG063 reduced the production of VEGF which was induced by $\mathrm{CoCl}_{2}$ stimulation. Based on this result, we investigated whether DIM decreases the level of mitochondrial ROS generation in $\mathrm{CoCl}_{2-}$ stimulated ARPE-19 cells. As shown by our results, DIM reduced the level of mitochondrial ROS (Fig. 4B). Subsequently, we examined the effects of YCG063 on the accumulation of HIF-1 $\alpha$ in $\mathrm{CoCl}_{2}$-stimulated ARPE-19 cells (Fig. 4C). The accumulation of HIF-1 $\alpha$ increased in the nuclei of the $\mathrm{CoCl}_{2}$ stimulated ARPE-19 cells; this increase was significantly reduced by treatment with YCG063.

Inhibitory effects of DIM on the secretion of VEGF through the inhibition of $N F-\kappa B$ activation. Since NF- $\kappa \mathrm{B}$ is a transcription factor that regulates the expression of VEGF (12), we investigated whether DIM inhibits the translocation of NF- $\kappa \mathrm{B}$ from the cytosol to the nucleus or NF- $\mathrm{BB}$ binding activity. First, the ARPE-19 cells were treated with the NF- $\kappa \mathrm{B}$ inhibitors, parthenolide and BAY 11-7082, prior to stimulation with $\mathrm{CoCl}_{2}$. Parthenolide $(2 \mu \mathrm{M})$ and BAY 11-7082 $(2 \mu \mathrm{M})$ caused a reduction in the production of VEGF induced by hypoxia $\left(\mathrm{CoCl}_{2}\right.$; Fig. 5A). The HIF-1 $\alpha$ inhibitor, PX-478, also caused a decrease in VEGF secretion. Western blot analyses using nuclear fractions revealed that the accumulation of $N F-\kappa B$ p 65 in the nucleus was markedly increased following treatment with $\mathrm{CoCl}_{2}$ alone; however, pre-treatment with DIM $(20 \mu \mathrm{M})$ reversed this trend (Fig. 5B). We then investigated the effects of DIM on the DNA-binding activity of NF- $\kappa \mathrm{B}$ using EMSA (Fig. 5C). Stimulation with $\mathrm{CoCl}_{2}$ caused a significant increase in the DNA-binding activity of $\mathrm{NF}-\kappa \mathrm{B}$, whereas treatment with DIM markedly reduced the $\mathrm{CoCl}_{2}$-induced DNA-binding activity of $\mathrm{NF}-\kappa \mathrm{B}$. Moreover, the upregulated translocation of NF- $\kappa \mathrm{B}$ p65 was significantly inhibited by treatment with YCG063 (Fig. 5B). These results indicate that the generation of ROS following exposure to hypoxia serves as an upstream signal for the activation of $\mathrm{NF}-\kappa \mathrm{B}$.

Effects of DIM on the phosphorylation MAPKs in $\mathrm{CoCl}_{2^{-}}$ stimulated ARPE-19 cells. It is well known that MAPK signaling molecules are able to regulate HIF-1 $\alpha$ activation (13). Therefore, in this study, we examined the effects of DIM on hypoxia-induced MAPK activation. The ARPE-19 cells were pre-treated with various inhibitors of signal transduction pathways, such as SB203580 for p38 MAPK, U0126 for ERK and SP600126 for JNK, prior to $\mathrm{CoCl}_{2}$ stimulation. Among these inhibitors, SP600126 did not affect VEGF production during hypoxia. However, SB203580 and U0126 reduced VEGF production which was induced by hypoxia (Fig. 6A). Based on these results, we investigated the effects of DIM on p38 MAPK and ERK activation induced by hypoxia. Pre-treatment with DIM resulted in a significant inhibition of $\mathrm{CoCl}_{2}$-induced p38 MAPK phosphorylation (Fig. 6B). However, DIM did not affect ERK phosphorylation during hypoxia. These results demonstrated that the inhibition of VEGF production by DIM in $\mathrm{CoCl}_{2}$-stimulated ARPE-19 cells was associated with the downregulation of p38 MAPK phosphorylation. We then investigated whether $\mathrm{p} 38$ MAPK phosphorylation is associ-
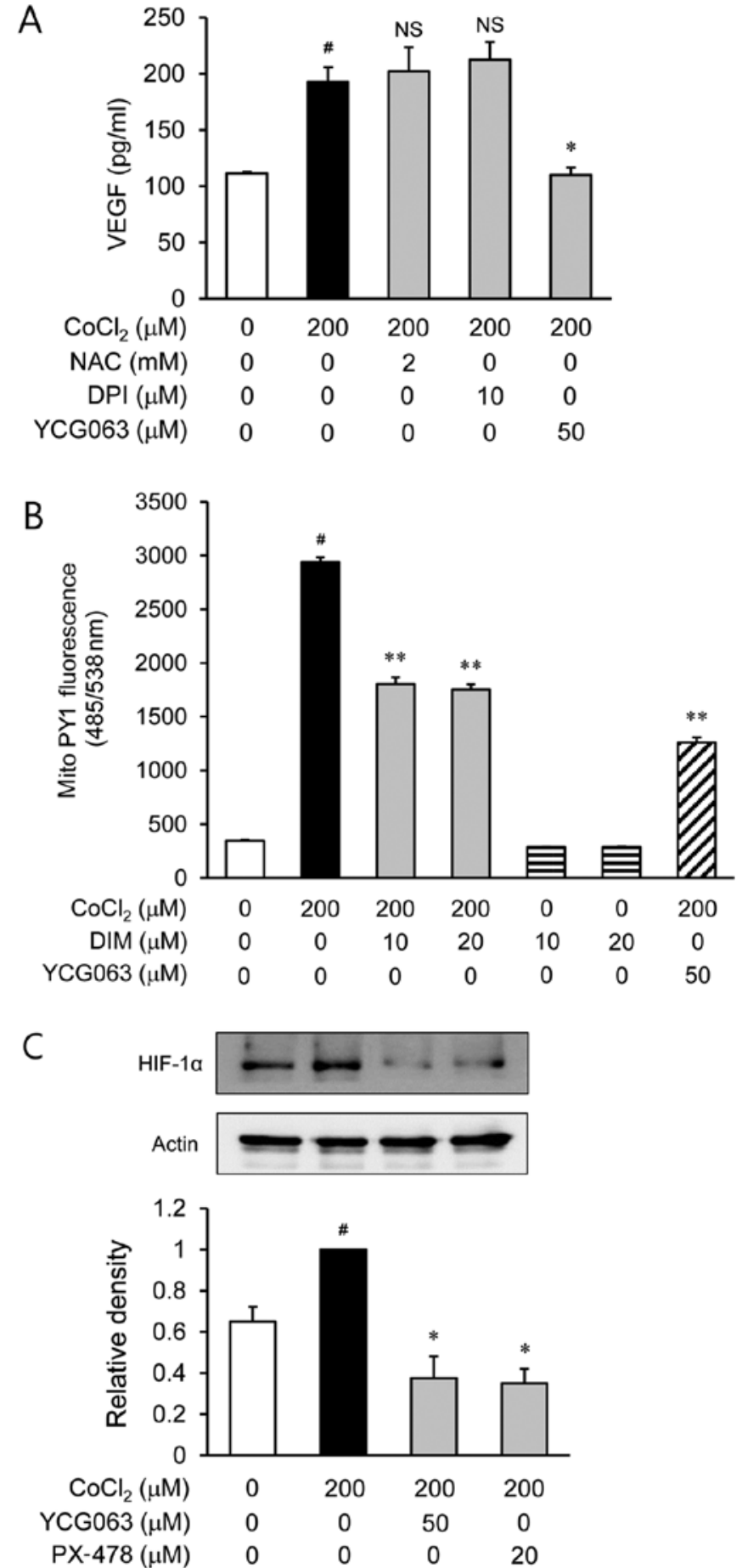

Figure 4. Effect of 3,3'-diindolylmethane (DIM) on the cobalt chloride $\left(\mathrm{CoCl}_{2}\right)$ stimulated production of mitochondrial reactive oxygen species (ROS) in ARPE-19 cells. (A) ARPE-19 cells were reated with NAC as a ROS scavenger, DPI as a NADPH oxidase inhibitor, and YCG063 as a mitochondrial ROS inhibitor for $30 \mathrm{~min}$ and then stimulated with $\mathrm{CoCl}_{2}$ for $24 \mathrm{~h}$. The production of vascular endothelial growth factor (VEGF) was measured using the corresponding enzyme-linked immunosorbent assay (ELISA) kits. Data are presented as the means \pm SEM and are representative of triplicate experiments. ${ }^{\#} \mathrm{p}<0.05$ vs. the control $\left(\mathrm{CoCl}_{2}\right.$ free $) ;{ }^{*} \mathrm{p}<0.05$ vs. $200 \mu \mathrm{M} \mathrm{CoCl}_{2}$ stimulation. NS, non-specific. (B) ARPE-19 cells were treated with DIM for $30 \mathrm{~min}$ and then stimulated with $\mathrm{CoCl}_{2}$ for $24 \mathrm{~h}$. The production of mitochondrial ROS was measured using a fluorescence microplate reader. ${ }^{*} \mathrm{p}<0.05 \mathrm{vs}$. the control $\left(\mathrm{CoCl}_{2}\right.$ free); ${ }^{* *} \mathrm{p}<0.01$ vs. $200 \mu \mathrm{M} \mathrm{CoCl}_{2}$ stimulation. (C) The hypoxia-inducible factor (HIF)-1 $\alpha$ levels in the nuclear protein extracts were determined by western blot analysis. ARPE-19 cells were treated with YCG063 for $30 \mathrm{~min}$ and then stimulated with $\mathrm{CoCl}_{2}$ for $6 \mathrm{~h}$. HIF-1 $\alpha$ was detected with a HIF-1a specific antibody. ${ }^{\#} \mathrm{p}<0.05$ vs. the control $\left(\mathrm{CoCl}_{2}\right.$ free); ${ }^{*} \mathrm{p}<0.05$ vs. $200 \mu \mathrm{M} \mathrm{CoCl}_{2}$ stimulation. 
A

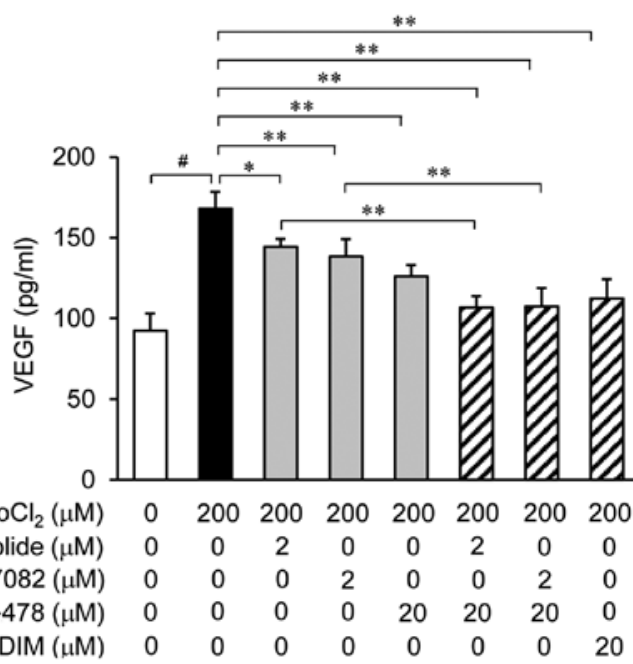

B
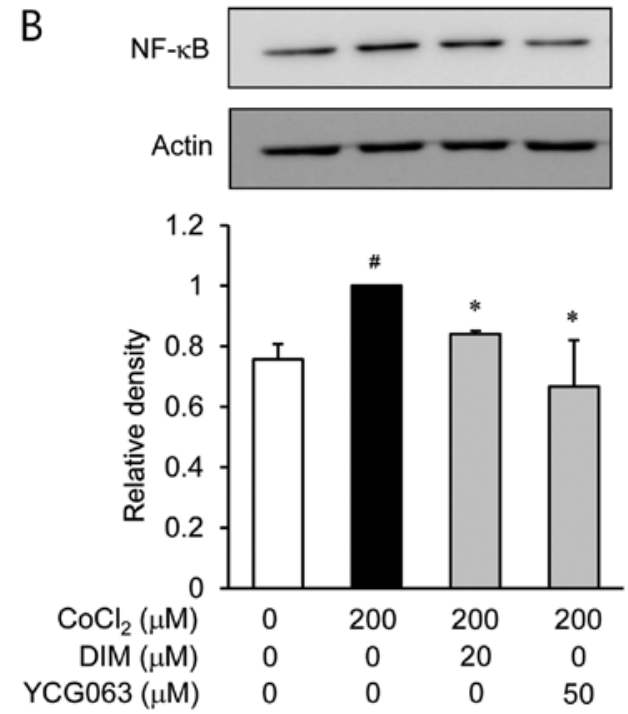

$\begin{array}{rccccc}\mathrm{C} \mathrm{CoCl}_{2}(\mu \mathrm{M}) & 0 & 200 & 200 & 200 & 200 \\ \mathrm{DIM}(\mu \mathrm{M}) & 0 & 0 & 10 & 20 & 0 \\ 100 \mathrm{x} \text { cold } & - & - & - & - & +\end{array}$

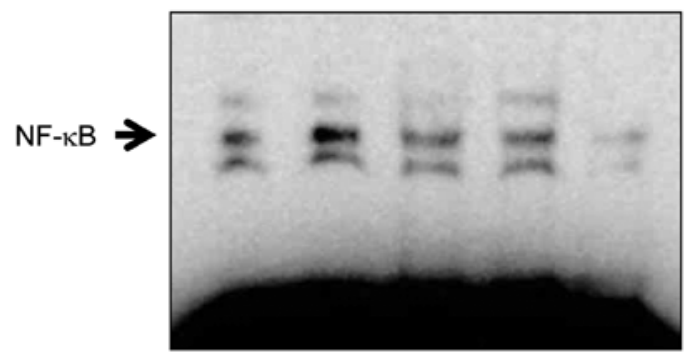

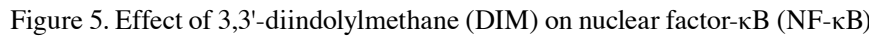
activity in cobalt chloride $\left(\mathrm{CoCl}_{2}\right)$-stimulated ARPE-19 cells. (A) The production of vascular endothelial growth factor (VEGF) was measured using the corresponding enzyme-linked immunosorbent assay (ELISA) kits. ARPE-19 cells were pre-treated with the NF-kB inhibitors, parthenolide or BAY 11-7082, and the HIF-1 $\alpha$ inhibitor PX-478 for $30 \mathrm{~min}$ in combination or alone and were then stimulated with $\mathrm{CoCl}_{2}$ for $4 \mathrm{~h} .{ }^{*} \mathrm{p}<0.05$ vs. the control $\left(\mathrm{CoCl}_{2}\right.$ free); ${ }^{*} \mathrm{p}<0.05$, ${ }^{* *} \mathrm{p}<0.01$ vs. $200 \mu \mathrm{M} \mathrm{CoCl}_{2}$ stimulation. (B) NF-kB levels in the nuclear protein extracts were determined by western blot analysis. ARPE-19 cells were treated with $20 \mu \mathrm{M}$ DIM and $50 \mu \mathrm{M}$ YCG063 for 30 min prior to $\mathrm{CoCl}_{2}$

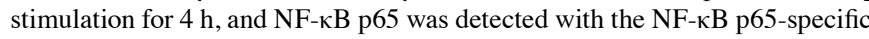
antibody. ${ }^{*} \mathrm{p}<0.05$ vs. the control $\left(\mathrm{CoCl}_{2}\right.$ free); ${ }^{*} \mathrm{p}<0.05$ vs. $\mathrm{CoCl}_{2}$ stimulation. (C) ARPE-19 cells were treated with DIM (10 or $20 \mu \mathrm{M})$ for 30 min prior to stimulation with $200 \mu \mathrm{M} \mathrm{CoCl}_{2}$. Nuclear extracts were prepared at $30 \mathrm{~min}$ and analyzed by electrophoretic mobility shift assay (EMSA) for the DNA-binding activity of NF-KB.
A

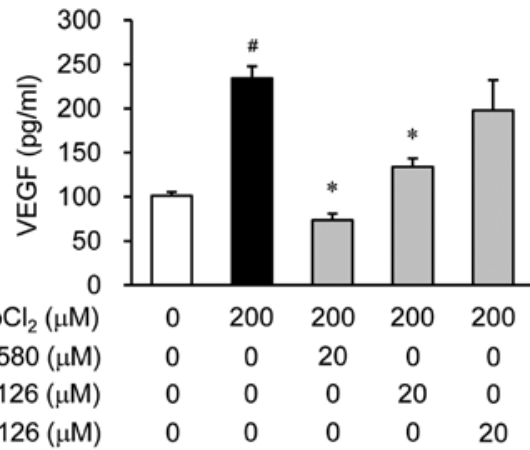

B
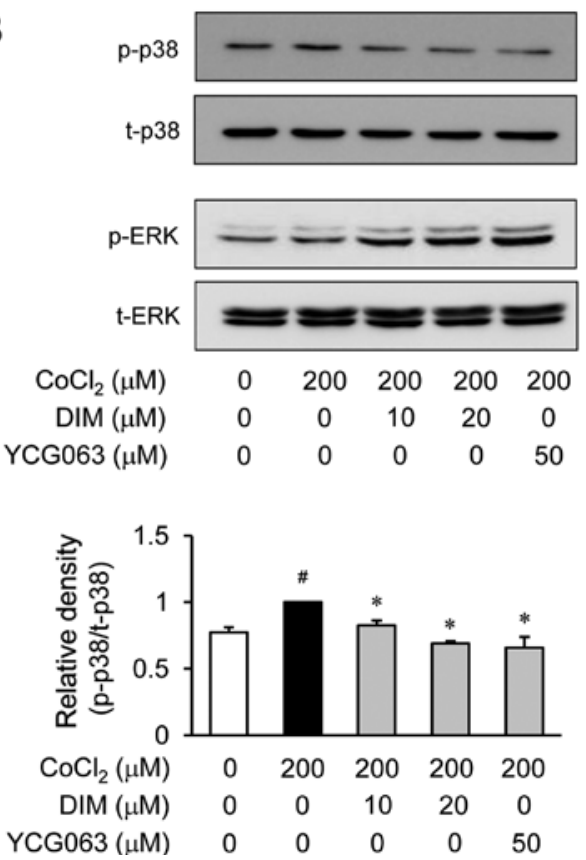

C
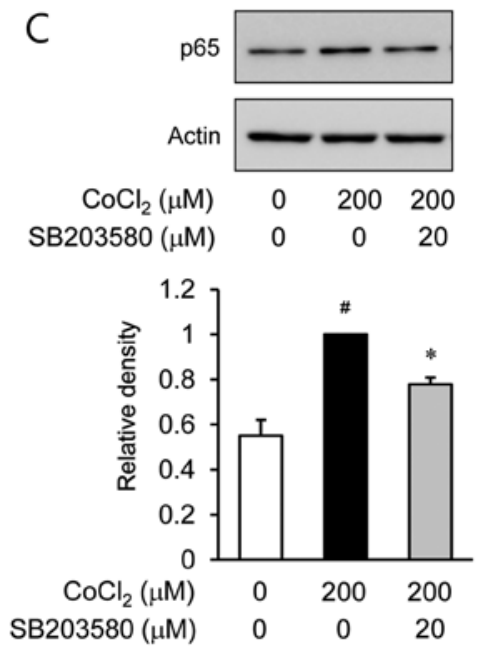

Figure 6. Effect of 3,3'-diindolylmethane (DIM) on the phosphorylation of mitogen-activated protein kinase (MAPK) in ARPE-19 cells following exposure to cobalt chloride $\left(\mathrm{CoCl}_{2}\right)$. (A) The levels of vascular endothelial growth factor (VEGF) in the culture medium were determined by enzyme-linked immunosorbent assay (ELISA). ARPE-19 cells were treated with SB203580 (a MAPK inhibitor), U0126 [an extracellular signal-regulated kinase (ERK)1/2 inhibitor], or SP600126 (a JNK inhibitor) $30 \mathrm{~min}$ prior to $\mathrm{CoCl}_{2}$ stimulation for $24 \mathrm{~h}$. (B) Cells were treated with DIM $(10$ or $20 \mu \mathrm{M})$ and YCG063 $(50 \mu \mathrm{M})$ $30 \mathrm{~min}$ prior to $\mathrm{CoCl}_{2}$ stimulation for $30 \mathrm{~min}$. Western blot analysis was performed to determine the levels of p38 MAPK and ERK phosphorylation. (C) The nuclear factor- $\mathrm{kB}(\mathrm{NF}-\mathrm{\kappa B})$ p65 levels in the nuclear protein extracts were determined by western blot analysis. ARPE-19 cells were treated with $20 \mu \mathrm{M}$ SB203580 for $30 \mathrm{~min}$ prior to $\mathrm{CoCl}_{2}$ stimulation for $4 \mathrm{~h}$, and NF- $\mathrm{kB}$ p65 was detected with the NF- $\mathrm{kB}$ p65-specific antibody. ${ }^{*} \mathrm{p}<0.05$ vs. the control $\left(\mathrm{CoCl}_{2}\right.$ free); ${ }^{*}<0.05$ vs. $\mathrm{CoCl}_{2}$ stimulation. 
ated with mitochondrial ROS generation. The ARPE-19 cells were treated with $\mathrm{CoCl}_{2}$ for $2 \mathrm{~h}$ in the presence or absence of YCG063, a mitochondrial ROS inhibitor. Pre-treatment with YCG063 resulted in a significant attenuation of $\mathrm{CoCl}_{2}$-induced p38 MAPK phosphorylation (Fig. 6B). These results indicate that the generation of mitochondrial ROS induced by exposure to hypoxia serves as an upstream signal for the induction of VEGF production by $\mathrm{p} 38$ MAPK activation. Furthermore, to elucidate the downstream signal responsible for the induction of VEGF production by p38 MAPK activation, we investigated $\mathrm{NF}-\kappa \mathrm{B}$ activation by western blot analysis of the cell nuclei. When the ARPE-19 cells were treated with the p38 MAPK inhibitor, SB203580, the translocation of $N F-\kappa B$ was reduced under hypoxic conditions (Fig. 6C).

\section{Discussion}

Under hypoxic conditions, RPE cells release various growth factors, resulting in angiogenesis, fibrovascular tissue formation and retinal ablation (14). Among the hypoxia-stimulated growth factors, VEGF is a pivotal regulator of vasculogenesis and angiogenesis in CNV (4). In the present study, we investigated whether DIM inhibits VEGF secretion from ARPE-19 cells stimulated with $\mathrm{CoCl}_{2}$ (to mimic hypoxic conditions). $\mathrm{CoCl}_{2}$ is commonly used as a hypoxia-mimetic agent as, similar to hypoxia, it blocks the degradation and thus induces the accumulation of HIF-1 $\alpha$ protein (15). As expected, the secretion of VEGF significantly increased under chemical hypoxic conditions without any cytotoxicity. However, the increased levels of VEGF secretion were significantly inhibited by treatment with 10 and $20 \mu \mathrm{M}$ DIM under hypoxic conditions (Fig. 2). This study demonstrates that DIM inhibits the $\mathrm{CoCl}_{2}$-induced production of VEGF by suppressing the activation of $\mathrm{NF}-\kappa \mathrm{B}$ and HIF-1 $\alpha$.

It has been reported that through the HIF transcriptional complex, hypoxia induces the production of $\operatorname{VEGF}(16,17)$. HIF-1 $\alpha$ plays a critical role in CNV. Therefore, the inhibition of the HIF pathway offers an attractive therapeutic strategy for CNV. We thus investigated whether DIM attenuates the translocation of HIF-1 $\alpha$ to the nucleus and binding to HRE of the VEGF promoter. Treatment with DIM attenuated HIF-1 $\alpha$ accumulation (Fig. 3A) and HIF-1 $\alpha$-dependent binding activity (Fig. 3B). To verify whether hypoxia induces the production of VEGF through the HIF transcriptional complex, we used an HIF-1 $\alpha$ inhibitor and siRNA against HIF-1 $\alpha$ under chemical hypoxic conditions. As expected, our results revealed that PX-478 (an inhibitor of HIF-1 $\alpha$ ) and siHIF-1 $\alpha$ inhibited VEGF production in the $\mathrm{CoCl}_{2}$-stimulated ARPE-19 cells, suggesting that DIM may be useful for ocular neovascularization through the downregulation of HIF-1 $\alpha$ activation.

It has been demonstrated that ROS induces the expression of VEGF (18) and is crucial for the induction of angiogenesis (19). To deter,ome whether ROS levels affect VEGF production, the $\mathrm{CoCl}_{2}$-stimulated ARPE-19 cells were pre-treated with NAC, DPI and YCG063 (Fig. 4A). Among these inhibitors of ROS, NAC and DPI did not affect VEGF production during hypoxia. However, YCG063 (an inhibitor of mitochondrial ROS) significantly decreased the production of VEGF. Based on this result, we investigated whether DIM decreases the level of mitochondrial ROS generation in $\mathrm{CoCl}_{2}$-stimulated ARPE-19 cells (Fig. 4B). As shown by the results of the fluorescence microplate analysis, DIM reduced the level of mitochondrial ROS generation. Since ROS regulates VEGF production through the induction of HIF-1 $\alpha$, we examined the effects of YCG063 against HIF-1 $\alpha$ accumulation in $\mathrm{CoCl}_{2}$-stimulated ARPE-19 cells by western blot analysis (Fig. 4C). The accumulation of HIF-1 $\alpha$ increased in the nuclei of the $\mathrm{CoCl}_{2}$-stimulated ARPE-19 cells. However, this increase was significantly reduced by treatment with YCG063. Taken together, the inhibition of mitochondrial ROS generation by DIM is consistent with inhibition of HIF-1 $\alpha$ accumulation and VEGF expression, which may result in reduced ocular neovascularization.

It has been reported that hypoxia induced by $\mathrm{CoCl}_{2}$ leads to increased ROS production, the activation of $\mathrm{NF}-\kappa \mathrm{B}$ and the induction of VEGF in human RPE cells (20). Therefore, in this study, we examined the effects of the NF- $\kappa \mathrm{B}$ inhibitors, parthenolide and BAY 11-7082, on the $\mathrm{CoCl}_{2}$-induced secretion of VEGF by ARPE-19 cells. Our results revealed that pre-treatment with parthenolide and BAY 11-7082 inhibited the secretion of VEGF under hypoxic conditions (Fig. 5A). However, pre-treatment with the HIF-1 $\alpha$ inhibitor, PX-478, had a greater inhibitory effect than pre-treatment with the NF- $\kappa \mathrm{B}$ inhibitors on $\mathrm{CoCl}_{2}$-stimulated VEGF secretion. Of note, the inhibition of both the HIF- $1 \alpha$ and NF- $\kappa \mathrm{B}$ pathways with a combination (Fig. 5A: parthenolide + PX-478 and BAY 11-7082 + PX-478, respectively) pre-treatment had the greatest inhibitory effect on VEGF secretion in the $\mathrm{CoCl}_{2}$-stimulated ARPE-19 cells. These results suggest that both signaling pathways, HIF-1 $\alpha$ and $\mathrm{NF}-\kappa \mathrm{B}$, play critical and synergistic roles in the production of VEGF. Based on the above results of the inhibitory effects of NF- $\kappa \mathrm{B}$ on VEGF secretion, we investigated whether DIM modulates NF- $\kappa \mathrm{B}$ activity in $\mathrm{CoCl}_{2}$-stimulated ARPE-19 cells. Since activated free $\mathrm{NF}-\kappa \mathrm{B}$ p65 enters the nucleus and induces VEGF expression, we investigated the nuclear translocation of the NF- $\kappa \mathrm{B}$ subunit, p65. Western blot analysis revealed that stimulation with $\mathrm{CoCl}_{2}$ induced the translocation of NF- $\kappa \mathrm{B}$ p65 into the nuclear compartment (Fig. 5B). However, the $\mathrm{CoCl}_{2}-$ induced the nuclear translocation of NF- $\kappa \mathrm{B}$ p 65 was inhibited in the presence of DIM. According to the EMSA data, $\mathrm{CoCl}_{2}$ stimulation increased the DNA-binding activity of $\mathrm{NF}-\kappa \mathrm{B}$. However, pre-treatment with DIM suppressed the $\mathrm{CoCl}_{2}$ induced DNA-binding activity of NF- $\kappa \mathrm{B}$ (Fig. $5 \mathrm{C}$ ). These data indicate that DIM inhibits NF- $\kappa \mathrm{B}$ activity in $\mathrm{CoCl}_{2}$-stimulated ARPE-19 cells by suppressing the nuclear translocation of p65 and, consequently, attenuates the production of VEGF.

A previous study indicated that MAPK signaling pathways are involved in regulating the expression of HIF-1 $\alpha$ and VEGF under hypoxic conditions (21). Based on this result, we hypothesized that anti-neovascularization mechanisms are related to MAPK pathways. To elucidate the regulatory mechanism of DIM in these processes, we investigated whether the MAPK signaling pathways are involved in regulating VEGF production. p38 MAPK- and ERK-specific inhibitors suppressed the secretion of VEGF. However, the JNK-specific inhibitor did not affect VEGF production during hypoxia (Fig. 6A). Subsequently, to investigate whether DIM regulates these pathways, we used western blot analyses to examine the phosphorylation of ERK and p38 MAPK. $\mathrm{CoCl}_{2}$ stimulation increased the phosphorylation of p38 MAPK (Fig. 6B). However, pre-treatment with DIM markedly reduced the phosphorylation of p38 MAPK in 
the $\mathrm{CoCl}_{2}$-stimulated ARPE-19 cells. Moreover, to examine the downstream pathway of p38 MAPK, we investigated whether the p38 MAPK inhibitor, SB203580, regulates NF- $\kappa$ B activation in $\mathrm{CoCl}_{2}$-stimulated ARPE-19 cells. According to the results of western blot analyses using nuclear fractions, we demonstrated that the accumulation of $\mathrm{NF}-\kappa \mathrm{B}$ p 65 in the nucleus was increased following treatment with $\mathrm{CoCl}_{2}$ alone. However, pre-treatment with SB203580 (a MAPK inhibitor) markedly reversed this trend. Of note, the MAPK inhibitor did not affect HIF-1 $\alpha$ accumulation during hypoxia (data not shown). Moreover, the phosphorylation of p38 MAPK was suppressed by pre-treatment with the mitochondrial ROS inhibitor, YCG063. Collectively, these results demonstrate that DIM inhibits the $\mathrm{CoCl}_{2}$-induced production of VEGF by regulating the mitochondrial ROS/p38 MAPK/NF- $\kappa \mathrm{B}$ signaling pathways in ARPE-19 cells. The MAPK pathways are upstream of NF- $\kappa \mathrm{B}$, but not HIF-1 $\alpha$.

In conclusion, the findings of this study demonstrated that hypoxia induced by $\mathrm{CoCl}_{2}$ increased the release of VEGF from cultured ARPE-19 cells. Pre-treatment with DIM significantly attenuated the production of VEGF in ARPE-19 cells under hypoxic conditions by suppressing the activation of the mitochondrial ROS/HIF-1 $\alpha$ and mitochondrial ROS/p38 MAPK/ $\mathrm{NF}-\kappa \mathrm{B}$ pathways. These data suggest that DIM is effective in preventing the hypoxia-induced secretion of VEGF in RPE cells and may be developed into a novel anti-angiogenic agent for AMD.

\section{Acknowledgements}

This study was supported the Basic Science Research Program through the National Research Foundation of Korea (NRF) funded by the Ministry of Education, Science and Technology (2013-R1A1A4A01011649). This study was also supported by the 2011 Research Grant from Kangwon National University.

\section{References}

1. Costagliola C, Agnifili L, Arcidiacono B, Duse S, Fasanella V, Mastropasqua R, Verolino M and Semeraro F: Systemic thromboembolic adverse events in patients treated with intravitreal anti-VEGF drugs for neovascular age-related macular degeneration. Expert Opin Biol Ther 12: 1299-1313, 2012.

2. Campochiaro PA: Ocular neovascularization. J Mol Med Berl 91: 311-321, 2013.

3. Simó R, Villarroel M, Corraliza L, Hernández C and GarciaRamírez M: The retinal pigment epithelium: Something more than a constituent of the blood-retinal barrier - implications for the pathogenesis of diabetic retinopathy. J Biomed Biotechnol 2010: 190724, 2010.

4. Yang XM, Wang YS, Zhang J, Li Y, Xu JF, Zhu J, Zhao W, Chu DK and Wiedemann P: Role of PI3K/Akt and MEK/ERK in mediating hypoxia-induced expression of HIF-1alpha and VEGF in laser-induced rat choroidal neovascularization. Invest Ophthalmol Vis Sci 50: 1873-1879, 2009.
5. Ke Q and Costa M: Hypoxia-inducible factor-1 (HIF-1). Mol Pharmacol 70: 1469-1480, 2006.

6. Banerjee S, Kong D, Wang Z, Bao B, Hillman GG and Sarkar FH: Attenuation of multi-targeted proliferation-linked signaling by 3,3'-diindolylmethane (DIM): From bench to clinic. Mutat Res 728: 47-66, 2011.

7. Brignall MS: Prevention and treatment of cancer with indole3-carbinol. Altern Med Rev 6: 580-589, 2001.

8. Shertzer HG and Senft AP: The micronutrient indole-3-carbinol: Implications for disease and chemoprevention. Drug Metabol Drug Interact 17: 159-188, 2000.

9. Lee SH, Kim JS, Yamaguchi K, Eling TE and Baek SJ: Indole-3carbinol and 3,3'-diindolylmethane induce expression of NAG-1 in a p53-independent manner. Biochem Biophys Res Commun 328: 63-69, 2005.

10. Kunimasa K, Kobayashi T, Kaji K and Ohta T: Antiangiogenic effects of indole-3-carbinol and 3,3'-diindolylmethane are associated with their differential regulation of ERK1/2 and Akt in tube-forming HUVEC. J Nutr 140: 1-6, 2010.

11. Yu BC, Lee DS, Bae SM, Jung WK, Chun JH, Urm SH, Lee DY, Heo SJ, Park SG, Seo SK, et al: The effect of cilostazol on the expression of matrix metalloproteinase-1 and type I procollagen in ultraviolet-irradiated human dermal fibroblasts. Life Sci 92: 282-288, 2013.

12. Kiriakidis S, Andreakos E, Monaco C, Foxwell B, Feldmann M and Paleolog E: VEGF expression in human macrophages is NF-kappaB-dependent: Studies using adenoviruses expressing the endogenous NF-kappaB inhibitor IkappaBalpha and a kinase-defective form of the IkappaB kinase 2. J Cell Sci 116: 665-674, 2003

13. Sodhi A, Montaner S, Miyazaki H and Gutkind JS: MAPK and Akt act cooperatively but independently on hypoxia inducible factor-1alpha in rasV12 upregulation of VEGF. Biochem Biophys Res Commun 287: 292-300, 2001.

14. Vadlapatla RK, Vadlapudi AD, Pal D, Mukherji M and Mitra AK: Ritonavir inhibits HIF-1 $\alpha$-mediated VEGF expression in retinal pigment epithelial cells in vitro. Eye (Lond) 28: 93-101, 2014.

15. Guo M, Song LP, Jiang Y, Liu W, Yu Y and Chen GQ: Hypoxiamimetic agents desferrioxamine and cobalt chloride induce leukemic cell apoptosis through different hypoxia-inducible factor-1 $\alpha$ independent mechanisms. Apoptosis 11: 67-77, 2006.

16. Ratcliffe PJ, O'Rourke JF, Maxwell PH and Pugh CW: Oxygen sensing, hypoxia-inducible factor-1 and the regulation of mammalian gene expression. J Exp Biol 201: 1153-1162, 1998.

17. Ratcliffe PJ, Pugh CW and Maxwell PH: Targeting tumors through the HIF system. Nat Med 6: 1315-1316, 2000.

18. Fay J, Varoga D, Wruck CJ, Kurz B, Goldring MB and Pufe T: Reactive oxygen species induce expression of vascular endothelial growth factor in chondrocytes and human articular cartilage explants. Arthritis Res Ther 8: R189, 2006.

19. Xia C, Meng Q, Liu LZ, Rojanasakul Y, Wang XR and Jiang BH: Reactive oxygen species regulate angiogenesis and tumor growth through vascular endothelial growth factor. Cancer Res 67: 10823-10830, 2007.

20. Cervellati F, Cervellati C, Romani A, Cremonini E, Sticozzi C, Belmonte G, Pessina F and Valacchi G: Hypoxia induces cell damage via oxidative stress in retinal epithelial cells. Free Radic Res 48: 303-312, 2014.

21. Gupta B, Chiang L, Chae K and Lee DH: Phenethyl isothiocyanate inhibits hypoxia-induced accumulation of HIF-1 $\alpha$ and VEGF expression in human glioma cells. Food Chem 141: 1841-1846, 2013. 